\title{
Determining and Measuring Key Psychological Characteristics: The Case of a National Basketball Federation
}

\author{
Author(s) \\ Kegelaers, Jolan; Wikkerink, Janneke; Oudejans, Raôul R.D. \\ DOI \\ 10.1123/cssep.2020-0035 \\ Publication date \\ 2021 \\ Document Version \\ Author accepted manuscript (AAM) \\ Published in \\ Case Studies in Sport and Exercise Psychology
}

Link to publication

\section{Citation for published version (APA):}

Kegelaers, J., Wikkerink, J., \& Oudejans, R. R. D. (2021). Determining and Measuring Key Psychological Characteristics: The Case of a National Basketball Federation. Case Studies in Sport and Exercise Psychology, 5(1), 52-60. https://doi.org/10.1123/cssep.2020-0035

If you believe that digital publication of certain material infringes any of your rights or (privacy) interests,

please let the Library know, stating your reasons. In case of a legitimate complaint, the Library will make the material inaccessible and/or remove it from the website. Please contact the library:

https://www.amsterdamuas.com/library/contact/questions, or send a letter to: University Library (Library of the University of Amsterdam and Amsterdam University of Applied Sciences), Secretariat, Singel 425, 1012 WP Amsterdam, The Netherlands. You will be contacted as soon as possible.

Download date:26 Apr 2023 
2 Determining and Measuring Key Psychological Characteristics: The Case of a National

\section{Basketball Federation}

4

Jolan Kegelaers ${ }^{\mathrm{a}, \mathrm{b}}$, Janneke Wikkerink $^{\mathrm{c}}$ \& Raôul R. D. Oudejans $\mathrm{s}^{\mathrm{b}, \mathrm{c}}$

6

7

a. Vrije Universiteit Brussel, Faculty of Psychology and Educational Sciences, Pleinlaan 2, 1050 Brussels, Belgium

b. Amsterdam University of Applied Sciences, Faculty of Sports and Nutrition, Dokter Meurerlaan 7, 1067 SM Amsterdam, The Netherlands

c. Vrije Universiteit Amsterdam, Department of Human Movement Sciences, Amsterdam Movement Sciences, and Institute for Brain and Behaviour Amsterdam, Van der 
Determining and Measuring Key Psychological Characteristics: The Case of a National

\title{
Basketball Federation
}

\begin{abstract}
This case study presents our structured and evidence-informed approach towards developing a psychological assessment instrument within a national basketball federation. To this end, a two-phase approach was adopted. During the first phase, a focus group with the coaches was conducted to determine the key psychological characteristics pertinent to the case environment. This resulted in ten identified key psychological characteristics. During the second phase, the results from the focus group were used to develop and conduct preliminary testing of a context-specific assessment instrument. Preliminary testing of the instrument was conducted, resulting in a refined instrument including nine characteristics. Based on the findings of our case study, we conclude this paper by outlining a number of reflections that can provide important considerations for sport psychologists, coaches and talent identification and development organizations looking to develop and implement psychological assessment within their programs.
\end{abstract}

Keywords: applied research; monitoring; profiling; psychological competences; psychological assessment 


\section{Determining and Measuring Key Psychological Characteristics: The Case of a National}

\section{Basketball Federation}

Psychological characteristics play a crucial role in successful talent development and elite performance (Dohme et al., 2019; Rees et al., 2016). Psychological factors are a key determinant for the quantity and quality of practice athletes engage in (e.g., Tedesqui \& Young, 2018) as well as the ability to perform under pressure (e.g., Swann et al., 2017), cope with and rebound from major challenges and adversities (e.g., Kegelaers \& Wylleman, 2019) and balance the demands of different life domains with athletic development (e.g., sport and study; De Brandt et al., 2018). Scholars have therefore called for sport psychologists, coaches and talent identification and development (TID) organizations to structurally integrate the development of psychological characteristics within talent development pathways (Blijlevens et al., 2018; Dohme et al., 2019). Within such an approach, psychological profiling or assessment can be used to facilitate and monitor the development of these characteristics and ultimately optimize talent development (Hill et al., 2019; Rees et al., 2016). With such psychological assessment we refer to the structured and systematic measuring of psychological characteristics through the use of psychometric instruments. Sport psychology already has a long history of using psychometric instruments in practice (e.g., O’Connor, 2004). Nevertheless, a number of challenges exist for TID organizations to integrate psychological assessments in their programs. Measuring psychological characteristics should occur strategically based on a clear understanding and operationalization of the most salient characteristics within a given context (O'Connor, 2004). However, coaches and practitioners may experience challenges delineating the most salient characteristics for their program, given the plethora of psychological constructs available in the literature. To illustrate, a recent systematic review of the psychological factors facilitative of youth sport development identified at least 19 different characteristics and skills (Dohme et 
al., 2019). Just some commonly heard terms within the applied field include constructs such as commitment, confidence, focus, grit, growth mindset, hardiness, mental toughness, motivation, perseverance, resilience, self-control, self-efficacy, self-regulation, and volition. In addition to the sheer number of constructs, the popularity of some of these buzzwords could lead to selection based on hype rather than a careful consideration of the most relevant characteristics within a given context.

Alternatively, some scholars have made attempts to present a universal set of psychological characteristics for athletic success (e.g., the 5C's, Harwood, 2008; Psychological Characteristics of Developing Excellence, MacNamara et al., 2010). Although insightful, these approaches can still fail to account for the contextual specificity of many psychological characteristics. Research shows that the relevance and importance of specific characteristics can differ for performance level (e.g., Rees et al., 2016), developmental stage (e.g., Blijlevens et al., 2018), type of sport (e.g., Blijlevens, 2019), or even for playing positions within a sport (e.g., Andrew et al., 2007). Such potential issues have commonly been recognized within more idiosyncratic self-driven assessment strategies, such as performance profiling (Bird et al., 2020). However, sport psychologists and coaches might find little guidance in the available literature to determine a relevant and comprehensive set of objective psychological characteristics pertinent across their particular context. The challenges of selecting the most appropriate psychological characteristics also translate to the selection of the most appropriate measurement instruments. A large number of psychometric instruments can be found within the literature aimed towards measuring specific psychological constructs. Moreover, other questionnaires have been developed to measure multiple psychological characteristics within a single instrument. For example, the Athletic Coping Skills Inventory-28 (ACSI-28; Smith et al., 1995) measures constructs such as coachability, concentration, or goal setting and mental preparations among others; whereas 

the Psychological Characteristics of Developing Excellence Questionnaire 2 (PCDEQ2; Hill et al., 2019) measures characteristics such as active coping, imagery and active preparation, or seeking and using social support. From an applied perspective, however, there still exists limited evidence to support the selection of one of these scales over another.

The case study presented in this article outlines a structured and evidence-informed approach towards developing an assessment instrument to measure psychological characteristics within an applied TID organization. Our purpose here is not to determine a definitive set of psychological characteristics, which is applicable across multiple contexts. Rather, we aimed to explore how an applied organization can systematically determine which characteristics are most salient to their context and compile an instrument to measure these, based on a robust scientific understanding of these psychological constructs. We recognize that different conceptualizations and definitions of psychological characteristics and associated terms (e.g., psychological skills) exist (e.g., Vealey, 1988). Within our approach we largely adhere to the recent conceptualization of psychological characteristics proposed by Dohme et al. (2017) based on an extensive literature review. They defined psychological characteristics as the "qualities of the mind" (p.157) which are thought to enable athletic success and the development of expertise (Dohme et al., 2017). These characteristics (e.g., motivation, self-confidence) are relatively stable but can still be developed through targeted interventions. As such, our focus was not necessarily on pure psychological skills. These are the specific learned strategies (e.g., relaxation, imagery) which can be used to develop or regulate psychological characteristics, either immediately or over time (Blijlevens et al., 2018; Dohme et al., 2017). Additionally, we also did not focus on pure personality traits (e.g., Big5; Allen et al., 2011), which are considered stable and largely untrainable, and therefore hold less practical implications within TID (Rees et al., 2016).

\section{Case Context}


This case study started with the explicit question formulated by a national female

111 basketball federation for support in the development of an instrument to measure

112 psychological characteristics in their organization. The federation includes a talent

113 development program, which aims to prepare young players (aged 15-21) for a durable career

114 within elite international basketball. The program contributes to this goal by giving athletes a

115 fundamental basis for their sport careers and their future social careers. It is a full-time

116 program including about 15-20 hours of training, with one or two matches per week. It offers

117 young talented basketball players the opportunity to combine training, study and living in the

118 same city. In addition to the talent development program, the federation is also responsible for

119 the national teams, including the senior national team, U20 national team, and the $3 \times 3$ senior

120 and U20 national teams. For this case study, all athletes within the talent development

121 program and national teams were included. This resulted in a total of 53 players, aged

122 between 15 and 29 years old $(M=20.3$ years, $S D=4.2$ years $)$. Three coaches ( 2 males, 1

123 female) also collaborated within the case, including the senior national team head coach (who

124 was also the talent development program head coach), the senior national team assistant

125 coach, and the U20 national team head coach. All three coaches were also involved in the

126 daily workings of the talent development program. The coaches ranged in age between 39 and

$12743(M=40.3$ years, $S D=1.3$ years $)$. On average, they had 14.7 years of coaching experience.

128 Our applied work - within this case and other settings - is in large part informed by

129 our work as academic researchers in addition to our applied experience. Both the first and

130 third author hold an academic position within sport and performance psychology as a primary

131 occupation. The first author has a background in clinical psychology before specializing and

132 obtaining a PhD in sport and performance psychology, and positions himself within

133 humanistic psychological approaches (Egan, 2018). The second author collaborated in this

134 case as part of obtaining her master's Sport Psychology degree. She has experience with 
135 coaching and applied sport psychology work in tennis, in addition to being a high-

136 performance athlete herself. The third author has a background in human movement sciences

137 and sport and performance psychology. He has much experience in research within applied

138 performance contexts (e.g., sports, music, dance, police work), with a specific focus on how

139 scientific knowledge can be transferred to actual practice in these domains. His work is

140 grounded within ecological psychology (Michaels \& Beek, 1995). We believe that applied

141 work should be informed by sound theory and empirical evidence. At the same time, our

142 philosophical approach in this project was a pragmatic one (Giacobbi et al., 2005). As such,

143 we were not interested in uncovering absolute truths or building theory. Rather, our aim was

144 to gain an evidence-informed perspective on 'what works' when trying to establish a practical

145 assessment instrument to measure psychological characteristics within a real-life TID

146 environment.

147 In line with the holistic ecological approach towards TID (Henriksen, 2015), we

148 believe that the environment around an athlete has a strong influence on the psychosocial

149 development of the athlete. This has the important implication that interventions should be

150 conducted "inside the athlete's environment and involving the environment as much as

151 possible-rather than removing them from their natural setting and into the practitioner's

152 office" (Henriksen, 2015, p.144). We argue that a psychological assessment instrument can

153 help coaches to understand the psychosocial functioning of their athletes and design

154 interventions to develop psychological characteristics within the daily practice environment.

155 Within such an approach, sport psychology practitioners can adopt a supporting role rather

156 than being the main intervention agent. Hence, the assessment instrument presented here was

157 designed to facilitate understanding of and discussion around key psychological

158 characteristics among coaches, athletes and sport psychologists; ultimately supporting the

159 development of these characteristics within the day-to-day work of the TID environment. 


\section{The Case}

In order to develop a pragmatic evidence-informed assessment instrument, we adopted a two-phase approach in this case study. During the first phase we tried to establish which specific psychological characteristics coaches believed to be the most relevant for their athletes and their specific TID organization. Based on the insights gained from the first phase, we developed an assessment instrument by drawing on existing validated psychometric instruments and conducted preliminary testing of the usability of this instrument during the second phase.

\section{Phase 1: Determining the key psychological characteristics}

In order to examine the coaches' perspectives on the most important psychological characteristics within their TID organization, we conducted a focus group with all three coaches involved in the TID. A semi-structured focus group guide was developed to direct the conversation. The focus group started with a general discussion about the importance of psychology for development and performance in basketball. From here, the discussion went more in-depth on the psychological characteristics that coaches believed to be important for their specific sport, athletes and organization. A particular focus point during the discussion was on the importance of psychological characteristics within different contexts. The multidimensional and dynamical nature of sports asks for a holistic approach when exploring psychological characteristics (Wylleman \& Rosier, 2016). Therefore, important psychological characteristics were asked in relation to training, competition and daily life outside sport.

Examples of probing questions included: "What characteristics are important in, for example, the training context?" and "Are these characteristics also important in other contexts?"

Dohme et al. (2017) highlighted the risk of using ordinary words (e.g., mindset, motivation) to label psychological characteristics. Such labels "assume a shared understanding" (p.136) whereas in reality coaches often construct their own understanding and meaning of these 
185

186

187

psychological constructs, leading to inconsistent use of terms and definitions. To counteract a misinterpretation of terminology, clear descriptions of each term used by the coaches was asked. Such probing questions included examples such as: "What does this psychological term mean exactly to you?" and "Can you further clarify what you mean by this term?" To further operationalize the psychological characteristics, coaches were also asked about the prototypical and antitypical observable behaviors they associated with the described characteristics. Examples of probe questions included: "What behavior would a player show who (does not) excel(s) in this characteristic?" and "When are these behaviors important?" The duration of the focus group was around 70 minutes. Subsequently, data from the focus group was analyzed and interpreted using latent thematic data analysis. To this end, the six phases described by Braun et al. (2016) were used to analyze, identify and structure patterns within the data. Based on the descriptions of the coaches, each theme was given a composite definition to describe the psychological characteristics. These definitions were then deductively compared to and matched with the scientific constructs which best encompassed said definition, even when coaches did not directly mention this specific scientific construct verbatim. Such deductive classification requires an interpretative activity and can arguably create a separation between the coaches' own perspectives and the obtained outcomes.

Nevertheless, in agreement with the coaches, we decided such interpretations were needed to move beyond colloquial understandings to a set of robust, scientifically informed and measurable constructs. The thematic data analysis resulted in ten psychological characteristics. Each characteristic is explained briefly below.

\section{Results from phase 1}

The first characteristic was labelled coachability. Coachability was defined as 'taking the opportunity to learn from coaches and their feedback; and actively use this information during practice and matches.' Within this theme, coaches mentioned the necessity of being a 
210 coachable player in order to reach one's maximal potential. This was described as a "an active

211 learning attitude," a "willingness to get feedback" and being "eager to hear what they can

212 improve":

213 The best players are really open to feedback. [...] If you speak to them they are not 214 immediately defending themselves and are not like "Yeah, but..", but more like "Great idea coach, we'll do it like this.". Or something like "I don't see it like that, because she was standing there and that is why I rotated my position.” Those are the real champions in my experience. [...] They want to be coached, they want to hear the truth. They have attitude like "tell me what to do, I want to get better." (C1) The second characteristic was labelled reflection. Reflection was defined as 'being able to reflect on prior situations and experiences, both on small or detailed events as well as the bigger picture; and use this knowledge to come up with improved strategies.' The coaches emphasized the importance of the ability to reflect as "a part of the development of one's learning ability":

Reflection is something that we want to teach our girls to do independently as well. [...] it is something which is also important in a group situation, and for them as individuals. Being better able to reflect after a shooting practice or at the end of a game or something, is important for them to learn. (C3)

As such, the coaches were constantly striving for players to reflect on their actions: We want the players to be trained in an environment where it is normal to reflect after a drill. Not only the opinion of the coach, but what do you think of it personally, what went well, and should we do different next time. [...] That they see what they need to do better next time: "these are my points of improvement." (C1)

234 the coaches as 'the belief that practice will eventually make you a better player, even when 
you make mistakes or have to put in a lot of extra effort.' Coaches described such a growth mindset as "the attitude that every minute you work on something will help to become a better player." In line with Dweck (2008), coaches also believed that such a growth mindset is a strong driver for athletes to initiate and engage in positive learning attitudes and activities by "stepping out of your comfort zone," "always taking the opportunities to improve themselves" and “owning responsibility” for one's own learning process.

The fourth psychological characteristic was labelled commitment. This was defined as 'being inspired and determined to play the game of basketball and to get the best out of yourself; and to act accordingly.' Coaches described commitment as "loving the sport,"

244 "being passionate" and "having the intrinsic motivation to play basketball." Furthermore, coaches argued that "being part of the program is a deliberate choice made by the players." Therefore, players were also expected to be fully committed to the elite sport lifestyle and the program: one's own talents and ability to achieve success.' The coaches described those confident athletes as: "They have the attitude like 'I want to get better. I don't come here to get told how good I am, because I already know that.' That is why the real champions who play in Europe stand out" (Coach 1). The coaches believed players who possessed confidence had a competitive advantage because they "do not directly feel offended by feedback," dare to 
260 "make their own choices," "share their opinions more often" and "have more joy playing the game."

The sixth characteristic was labelled competitiveness. This was defined as 'the desire and determination to win and be better than other players.' The coaches described this as

264 "having the mentality of breaking down the opponent," the "killer instinct" or an attitude of "I want to be the best and I'm going to be the best." Behaviorally, competitive athletes were believed to always strive for their best performance as well as trying to be better than other athletes on every task they do. This occurred during competition, but also during practice when competing against teammates. Importantly, the coaches also believed that a fine balance between this competitiveness and still enjoying the game would lead to the most optimal performance.

The seventh psychological characteristic was labelled focus. This was defined as 'the having "the right focus" before and during games as:

As soon as you are on the floor you are involved with every process of the warmingup and the game, which goes on for two and a half hours. And maybe it is different for one person than it is for another, but the choice that you make when you step on the court is to be totally involved and to know what is going on. Put on your stuff and be ready to play a game. (C3)

The coaches argued that such focus or "being mentally and cognitively completely engaged with the match [or training]" reflects a quality that could differentiate the good pro-players from lower-level players. 
opponents or simply a bad play: "Within the course of the game, how do you react on missing a shot or making a bad pass on defense? Not only your own reaction, but also how your reaction reflects on your own teammates and your opponents" (C2). Moreover, coaches also emphasized the importance of resilience and coping with adversity in the longer term. For example, after a though loss or other types of setbacks:

The first two games [of a tournament] were great, but the third game they got a pretty big slap in the face and they were not yet recovered in the next match so to say. It takes quite long before they fully recover. [...] It's not only coping under pressure, it is also managing stress and being adaptive. Like "this is what just happened, what is next for me?" Here I see a really big difference with the real champions. (C1) push through challenging situations and continue striving towards one's goal, without giving up before this goal is reached.' This perseverance was described by the coaches using terms such as "showing grit," "muddling through," "remain stoic," "embracing the grind" and "being persistent." The coaches argued that the essence of having perseverance reflected the ability to maintain effort and strive for one's goals, without giving up before the goal is reached. Again, coaches believed this perseverance, both in training and during competition, was one of the characteristics differentiating top-level players with those of a lower level: You know, they just don't quit. That is what we see with our national players, so the best players that we have, they don't think about quitting. They just have this idea of, defined as 'adapting to the team rules and culture, embracing your role and being positive alright, the next time I just try something else. (C1) towards your teammates.' According to the coaches, being a team player meant "honoring your existing commitments [to the team]," "adapting to the team rules and culture," 
310 "accepting your role" and acting accordingly, demonstrating "positive verbal and non-verbal

311 communication" towards the rest of the team and coaching staff, to "encourage your

312 teammates" and, overall, trying to provide a positive impact on the rest of the team.

313 In sum, the aim of the first phase was to establish the key psychological characteristics

314 pertinent to the specific case environment, as indicated by the coaches. In total, 10 key

315 characteristics were identified. Although some characteristics seemed to be mentioned

316 slightly more in relation to certain athletes (e.g., commitment appeared somewhat more

317 important for younger athletes moving to the boarding school), coaches mostly discussed

318 these characteristics as important for all their athletes, without distinction based on age or

319 position. Based on the coaches' own detailed descriptions of the different relevant

320 characteristics and associated behaviors within different TID contexts, we developed

321 composite definitions for each of the relevant characteristics. These composite definitions

322 were used to guide the development of an assessment instrument during the second phase.

323 Phase 2: Development and testing of the psychological assessment instrument

324 Instrument development

325 Based on the information gained in the first phase, we developed a pragmatic

326 evidence-informed psychological assessment instrument to measure each of the identified

327 relevant psychological characteristics. To this end, the literature was scanned to find suitable

328 scales or sub-scales for each characteristic. As highlighted earlier, colloquial understandings

329 of psychological terms might differ from scientific conceptualizations (Dohme et al., 2017).

330 As such, we compared the latent meanings of each characteristic, captured within the

331 composite definitions rather than the explicit terminology used by the coaches, with the

332 existing literature (e.g., the construct resilience was not mentioned verbatim, but captured a

333 specific part of the coaches' experiences). To be selected, each scale had to be validated and

334 have an acceptable demonstrated validity and reliability. Furthermore, as the aim of the 
335

assessment instrument was to provide a parsimonious and pragmatic instrument for use in a real-life TID organization, we also tried to select relatively short scales. A complete overview of the specific scales for each psychological characteristic is outlined below.

Coachability was measured using the coachability sub-scale of the ACSI-28 (Smith et al., 1995). This sub-scale includes four items scored on a 4-point Likert scale, ranging from 1 (Almost never) to 4 (Almost always). An example of items included in this scale is "If a coach criticizes or yells at me, I correct the mistake without getting upset about it." Reflection was measured using the reflection sub-scale of the Self-Regulation of Learning Self-Report Scale (SRL-SRS; Toering et al., 2012). This scale includes five items scored on a 5-point Likert scale, ranging from 1 (Strongly disagree) to 5 (Strongly agree). An example of one of the items includes "I evaluate the events that I experienced, so that I can learn from them."

Growth mindset was measured using the Conceptions of the Nature of Athletic Ability Questionnnaire-2 (CNAAQ-2; Biddle et al., 2003). The CNAAQ-2 includes 12 items scored on a 5-point Likert scale, ranging from 1 (Strongly disagree) to 5 (Strongly agree). The items include examples such as "You need to have certain 'gifts' to be good at sport."

Commitment was measured using the enthusiastic commitment sub-scale from the Sport Commitment Questionnaire-2 (SPQ-2; Scanlan et al., 2016). This sub-scale consists of six items scored on a 5-point Likert scale, ranging from 1 (Strongly disagree) to 5 (Strongly agree). An example item includes "I am dedicated to keep playing this sport." Confidence was measured using the self-confidence sub-scale of the Psychological Skills Inventory of Sports, Youth Version - Short form (Milavic et al., 2019). The selfconfidence sub-scale includes three items scored on a 5-Point Likert scale, ranging from 1 (Almost never) to 5 (Almost always). Examples of such items include "I can usually remain confident even through one of my poorer performances." 
Competitiveness was measured using the desire to excel-social achievement sub-scale

of the SPQ-2 (Scanlan et al., 2016). This sub-scale consists of five items scored on a 5-point

Likert scale, ranging from 1 (Strongly disagree) to 5 (Strongly agree). Items included for example "I push myself to win every time I compete in this sport."

Focus was measured using the concentration sub-scale of the ACSI-28 (Smith et al., 1995). This sub-scale contained four items scored on a 4-point Likert scale, ranging from 1 (Almost never) to 4 (Almost always). It included items such as "When I am playing sports, I can focus my attention and block out distractions."

Resilience was measured using the brief resilience scale (Smith et al., 2008). The brief resilience scale encompasses six items scored on a 5-point Likert scale, ranging from 1 (Strongly disagree) to 5 (Strongly agree). This includes items such as "I usually come through difficult times with little trouble." scale (Duckworth et al., 2007). This sub-scale contained six items on a 5-point Likert scale, ranging from 1 (Not at all like me) to 5 (Very much like me). Items included examples such as "I finish whatever I begin."

Finally, being a team player was measured using the interpersonal skills sub-scale of the Sport Mental Training Questionnaire (Behnke et al., 2019). The interpersonal skills subscale included four items scored on a 5-point Likert scale, ranging from 1 (Strongly disagree) to 5 (Strongly agree). Examples of items in this sub-scale include "I understand my role, and 380 the role of others on my team and how it all fits into the greater system." These 10 scales resulted in an initial assessment instrument containing 55 items. Prior to use in the case setting, we pilot tested the instrument with three female national level tennis players aged fifteen and sixteen. These tennis players were chosen as a convenience sample as 384 they had a similar profile (i.e., active within a high-performance talent academy), were aged 
around the lower age limits of the players within the case environment and already worked with the second author. During the pilot study, the participants were asked to complete the instrument and note any difficulties they found in the items and instructions or any additional questions that they had. The instructions and questions were understandable and clear, but the pilot study showed that there was a need to accentuate the context of the questions, that is, the sport context. In the final form of the assessment instrument, the context of the questions was therefore further highlighted. The time to complete the instrument was approximately 15 minutes, which matched our aim to develop a brief and accessible instrument.

\section{Instrument testing}

After completing the instrument development and pilot testing, the athletes within the case environment were all asked to complete the assessment instrument. Due to the COVID19 pandemic, we were necessitated to administer the instrument via online survey software through the coaches, with three reminders being sent after one, two and three weeks respectively. The survey itself started with a description of the aim (i.e., 'to help coaches better understand you and how you practice your sport') and instructions (i.e., 'please answer as truthfully as possible, there are no right or wrong answers') for completing the instrument. The athletes were also asked to complete some demographics (e.g., age, playing position, years since starting to play competitive basketball) in addition to the 10 psychometric scales.

404 In total, 42 players out of 53 players involved in the case environment completed the full 405 instrument (response rate $=79 \%$ ).

406 We also wanted to compare the results from the assessment instrument with the 407 coaches' own perceptions of the psychological characteristics. As such, coaches were asked to 408 rank their players on each of the 10 psychological characteristics. Rather than doing this for 409 the whole group, coaches did this for a sub-set of 21 players. The reasons for this were 
410 twofold. First, from a pragmatic perspective, doing this for a limited set of players was

411 considered to be more time efficient; an important consideration for the coaches during the

412 uncertainty of the COVID-19 crisis. Second, the 21 included athletes were all players who

413 were involved within the daily training academy, and thus, excluded the national team

414 players. Given the more frequent (i.e., daily) interactions with these 21 players, it was

415 believed that coaches might have a better perspective on each athlete's strength and

416 weaknesses when it comes to the psychological characteristics. Practically, coaches received

417 the written composite definition for each of the 10 characteristics and were asked to rank their

418 players in descending order for their possession of each characteristic. Aggregates of the

419 coach rankings were subsequently compared with the athletes' own scores on each of the 420 characteristics.

The main results of the assessment instrument are summarized in Table 1. Basic

422

423

424

425

426

427

430

431

432

433

434 descriptive statistics demonstrate that mean scores for all characteristics are relatively high. Although this is not necessarily unexpected within an elite sport organization, it suggests a ceiling effect. Although we should be careful with comparing averages of different scales (with a different number of items and different anchors), the athletes seemed to score themselves highest on characteristics such as commitment, competitiveness, reflection and coachability; whereas they tended to score themselves lower on characteristics such as focus, resilience and confidence. Also included in Table 1 are the Cronbach's alpha scores for each scale. Cronbach's alpha is a measure to assess the internal consistency, or reliability, of a particular scale (Taber, 2018). Within our case study, only the constructs reflection $(\alpha=.73)$, commitment $(\alpha=.83)$, confidence $(\alpha=.85)$, and resilience $(\alpha=.72)$ scored within the typically considered range for good internal consistency $(.95 \geq \alpha \geq .70)$. However, as Taber (2018) highlighted, lower internal consistency scores do not always need to be problematic, especially for scales with a limited number of items administered in a relatively small sample. 
435 As such, internal consistency for coachability $(\alpha=.58)$, growth mindset $(\alpha=.65)$, focus $(\alpha=$ $436.58)$, perseverance $(\alpha=.68)$ and team skills $(\alpha=.53)$ might still be considered acceptable, 437 especially for applied purposes. Only the construct competitiveness $(\alpha=.39)$ showed an 438 unacceptable internal consistency. As such, we decided to remove the competitiveness scale 439 from the final instrument.

440 Spearman's rank correlations coefficients $\left(r_{\mathrm{s}}\right)$ were used to calculate the correlations 441 between the relative rankings from the coaches and the athletes' scores on the assessment 442 instrument (see last column of Table 1). Only growth mindset $(r=-.46, p=.035)$ and 443 resilience $(r=-.47, p=.033)$ demonstrated significant moderate correlations. Some overlap 444 also seemed to be present between the athletes' and coaches' ratings for confidence $(r=-.41)$, 445 being a team player $(r=-.35)$ and focus $(r=-.33)$, which nevertheless failed to reach 446 significance. Overall, the findings suggest that there was relatively low agreement between

447 the coaches' perceptions and the athletes' scores on the psychological assessment instrument. 448 A number of potential explanations might be formulated for this finding. First, it is unclear to 449 which extent coaches have an accurate assessment of their athletes' possession of 450 psychological characteristics. Some characteristics, such as reflection, result from primarily 451 internal processes and may therefore not easily be observable for coaches. Conversely, more 452 overt characteristics with stronger expected links to observable behaviors, such as 453 commitment or perseverance, also failed to demonstrate strong correlations. Alternatively, 454 athletes themselves might find it difficult to realistically evaluate their own possession of 455 psychological characteristics or feel tempted to respond in a socially desirable manner.

456 Finally, intercorrelations between the different psychological characteristics were also 457 calculated using Pearson correlation coefficients, as illustrated in Table 2. ${ }^{1}$ Dohme et al.

\footnotetext{
${ }^{1}$ Note: commitment is still included in the correlation table, despite being omitted from the final assessment instrument based on its poor internal consistency.
} 
458 (2019) highlighted that many overlaps exists between common psychological constructs, as

459 well as synonymous use of terminology. As such, we used the intercorrelations to explore

460 how strongly different constructs were related to each other, as a potential sign of overlap. In

461 general, we found limited correlations between the different constructs, with the few

462 significant correlations being only small to moderate $(r \mathrm{~s}<.43)$. Although by no means

463 conclusive as a test for discriminatory validity, this finding suggests limited redundancy

464 within or overlap between the selected 10 psychometric scales. As such, each construct seems

465 to hold a distinct value within the TID organization.

466 In sum, we developed and conducted some early testing for a psychological

467 assessment instrument within an applied TID organization. Based on the evaluations of the

468 internal consistency of the different scale, the decision was made to drop the competitiveness

469 scale, resulting in a final instrument measuring nine characteristics (the final instrument can

470 be found as supplementary material). The evaluations of the coaches involved in this project

471 were highly positive and they believed the instrument could be of great added value for their

472 organization going into the future. However, some potential issues were also revealed during

473 the early testing of the instrument, including the questionable internal consistency of some

474 scales, the limited agreement between coaches and athletes, and the potential for social

475 desirability and ceiling effects. We believe these issues do not necessarily impede the

476 usability of the developed instrument. However, they raise some important considerations for

477 how, when and why this instrument might be useable. We will reflect further on these

478 considerations and examine how they might be relevant for other TID contexts within the

479 final section of this case study.

\section{Case Reflections}

The aim of this case study was to outline a structured and evidence-informed approach

482 towards developing an assessment instrument to measure psychological characteristics within 
an applied TID organization. It was not our aim to develop a definitive measurement instrument applicable to a wide range of contexts, nor was it our goal to assess the psychometric qualities of this instrument. Rather we hope that within this paper we illustrate how coaches, sport psychologists or other TID stakeholders can systematically approach the development and use of psychometric assessment within their organization, as well as offer some critical reflections. environment, which were later adjusted to nine characteristics within the instrument. When looking at these characteristics, we find some overlap with previous studies exploring key

492 psychological characteristics within different sport environments. For example, Blijlevens et 493 al. (2018) also identified focus, confidence, perseverance and competitiveness in their study with top-level gymnasts. Similarly, Dohme et al. (2019) identified confidence, competitiveness, resilience and focus as crucial psychological characteristics within youth sports. However, the differences among the psychological characteristics identified in this case study and other studies (see also e.g., Harwood, 2008; MacNamara et al., 2010), also highlights the potential context specificity of many of these psychological characteristics. As such, TID organizations would do well to carefully and strategically outline the characteristics most pertinent to their organization, rather than adhering to a single existing framework. Although we focused on the perspective of coaches in our case study, practitioners looking to 502 determine a similar context-specific set of crucial psychological characteristics might also 503 consider the perspectives of athletes and other stakeholders (e.g., sport psychologists) within 504 the TID organization.

As we explored the psychological characteristics pertinent to our specific case environment, characteristics were mostly discussed as important for all players. Nevertheless, 507 we recognize that there can still be considerable contextual differences even for the athletes 
508 within this environment. For example, within the total sample, athletes from a relatively broad age range were included. These players were often situated at different stages within their career. The younger players were members of the academy, hopeful for a professional career;

511 whereas the older players were already established national team members. It would seem

512 likely that the relative importance of the identified psychological characteristics might differ

513 among these athletes. A next step could therefore be to design a development pathway,

514 outlining the most important characteristics per development stage and pinpointing the

515 relative priorities for development per stage (see Blijlevens, 2019).

516 Within this case study, we are also not looking to uncritically endorse the constructs

517 underlying the psychological assessment instrument. We recognize that many psychological 518 constructs gain considerable hype and attention within the applied field; whereas in reality 519 science is murky and key constructs regularly have their validity questioned. For example, 520 despite its wide popularity, the concept of growth mindset - or at least its proposed universal 521 positive impact - has increasingly been called into question (e.g., Sisk et al., 2018). However, 522 by clearly defining, operationalizing and monitoring psychological characteristics, coaches 523 can move beyond colloquial understandings of a certain construct and evaluate the relevance of said characteristic within their TID environment over time.

When developing an assessment instrument like the one presented in this case study, a

526 crucial consideration is of course how this instrument should be used. Some scholars have

527 tentatively suggested that psychological assessment can provide a useful tool for talent

528 selectors (e.g., Tedesqui \& Young, 2018). Indeed, many stakeholders within the applied field 529 can be tempted to use psychological assessment for the purpose of talent selection, given the 530 constant pressures to gain a competitive edge in their selection procedures. However, we 531 would argue against such a use of psychological assessment for a number of reasons. First, it 532 has been noted that many psychometric instruments used within sport psychology do not meet 
533 the highest validation standards (Andersen et al., 2007). Although all scales used in our case 534 study were validated and published, several of these scales still lacked basic robust internal 535 consistency. Again, we do not believe this precludes any usability of these scales within an 536 applied setting. However, it raises questions concerning the validity of these measures to 537 guide high-impact decisions such as talent selection. Second, there also exist the previously 538 mentioned potential issues of a lack of self-insight, ceiling effects and particularly social 539 desirability. Social desirability refers to the conscious or unconscious tendency to rate items 540 in line with the perceived socially desirable responses, rather than in a way that accurately 541 reflects one's own feelings or attitudes; and has long been recognized as an important issue

542 regarding the use of self-report measures. However, such issues of socially desirable

543 responses would likely increase exponentially when athletes are aware of the considerable 544 impact good test scores can have on their further athletic career, further calling into question 545 the validity of psychometric instruments for talent selection purposes.

546 Third, too little is known about how scores on these validated questionnaires link up 547 with actual real-life behaviors. Although we know psychological characteristics are important 548 within talent development, we do not know the effect size that an increase of, for example, 549 one point on a psychometric scale has on corresponding real-life behaviors (Andersen et al., 550 2007). Finally, too little knowledge is still available on how and to which extent these 551 important characteristics can be developed (Rees et al., 2016). Some authors have suggested 552 that psychological characteristics reflect relatively stable factors (e.g., Dohme et al., 2017), 553 whereas others have suggested that psychological characteristics hold much more room for 554 development (Blijlevens et al., 2018). A "snapshot" style assessment for talent selection 555 purposes therefore does not take into account the dynamic and temporal aspects of the 556 development of such psychological characteristics (Den Hartigh et al., 2018; Hill et al., 2019). 
557 In sum, currently the evidence is not there to advocate the use of psychological assessment to 558 guide talent selection.

Instead, we would argue that psychological assessment is better used for development

560 purposes. Coaches or practitioners might use psychometric instruments to track dynamic

561 changes within athletes' psychological characteristics over time (Den Hartigh et al., 2018). Of

562 course, users should still be cognizant of the previously mentioned issues. However, by using

563 the instrument to track changes over time some of these issues could be somewhat mitigated.

564 For example, when systematically used in combination with applied efforts to develop

565 psychological characteristics, athletes might actually increase their self-insight and perceive

566 less incentives to answer in a socially desirable manner. In this regard, coaches may even

567 expect scores to decrease in certain circumstances. Not because athletes actually decrease in

568 their possession of psychological characteristics, but rather because they gain a more realistic

569 perspective on their own strengths and weaknesses with regards to the specific characteristic.

570 Furthermore, by using psychological assessment instruments systematically over time they

571 can also be linked to changes in real-life behaviors (Andersen et al., 2007). As such, we

572 strongly agree with Hill et al. (2019), suggesting that psychological assessment should ideally

573 be used as a part of a triangulation process, complemented with other indicators such as

574 behavioral observations, performance parameters and face-to-face discussions.

575 As part of this triangulation process, we believe the strongest value of a psychological

576 assessment instrument such as the one presented in this case actually lies in its use as a

577 reflection tool. Data from our case illustrates that agreement between coaches' and athletes'

578 perspectives is not always very high when it comes to certain psychological characteristics.

579 We believe that this should not necessarily be a negative. Rather, the scores can be used as a

580 starting point for a non-judgmental discussion whereby coaches, athletes and sport 
581 psychologists help each other gain more insight into one's own thoughts, feelings and 582 behaviors.

583 In conclusion, although the extant literature shows strong support for the importance

584 of psychological characteristics within talent development, no clear guidelines exist for how

585 this knowledge should be used within applied settings, particularly with regards to

586 psychological assessment. Within this paper, we presented our approach to develop an

587 evidence-informed assessment instrument within an applied TID organization. It was not our 588 goal to build theory or validate the instrument presented here but rather to outline a strategic

589 approach towards developing such an instrument. Based on the findings in our case study, we

590 have presented a number of key reflections that can provide important considerations for TID

591 organizations looking to develop and implement psychological assessment within their 592 programs. 


\section{References}

594 Allen, M. S., Greenlees, I., \& Jones, M. (2011). An investigation of the five-factor model of personality and coping behaviour in sport. Journal of Sports Sciences, 29(8), 841-850. https://doi.org/10.1080/02640414.2011.565064

597

598

Andersen, M. B., McCullagh, P., \& Wilson, G. J. (2007). But what do the numbers really tell us?: Arbitrary metrics and effect size reporting in sport psychology research. Journal of Sport \& Exercise Psychology, 29, 664-672.

Andrew, M., Grobbelaar, H. W., \& Potgieter, J. C. (2007). Positional differences in sport psychological skills and attributes of rugby union players. African Journal for Physical, Health Education, Recreation and Dance, 321-334.

Behnke, M., Tomczak, M., Kaczmarek, L. D., Komar, M., \& Gracz, J. (2019). The Sport Mental Training Questionnaire: Development and validation. Current Psychology, 38(2), 504-516. https://doi.org/10.1007/s12144-017-9629-1

Biddle, S. J. H., Wang, C. K. J., Chatzisarantis, N. L. D., \& Spray, C. M. (2003). Motivation for physical activity in young people: Entity and incremental beliefs about athletic ability. Journal of Sports Sciences, 21(12), 973-989. https://doi.org/10.1080/02640410310001641377

Bird, M. D., Castillo, E. A., \& Luzzeri, M. (2020). Performance profiling: Theoretical foundations, applied implementations and practitioner reflections. Journal of Sport Psychology in Action, 0(0), 1-13. https://doi.org/10.1080/21520704.2020.1822970

Blijlevens, S. J. E. (2019). Performance behaviour in elite sports (published doctoral dissertation). VUBPRESS.

Blijlevens, S. J. E., Elferink-Gemser, M. T., Wylleman, P., Bool, K., \& Visscher, C. (2018). Psychological characteristics and skills of top-level Dutch gymnasts in the initiation, development and mastery stages of the athletic career. Psychology of Sport and Exercise, 
38, 202-210. https://doi.org/10.1016/j.psychsport.2018.07.001

Braun, V., Clarke, V., \& Weate, P. (2016). Using thematic analysis in sport and exercise research. In B. Smith \& A. C. Sparkes (Eds.), Routledge Handbook of Qualitative Research in Sport and Exercise (pp. 191-205). Routledge.

De Brandt, K., Wylleman, P., Torregrossa, M., Schipper-Van Veldhoven, N., Minelli, D., Defruyt, S., \& De Knop, P. (2018). Exploring the factor structure of the Dual Career Competency Questionnaire for Athletes in European pupil- and student-athletes. International Journal of Sport and Exercise Psychology, 1-18. https://doi.org/10.1080/1612197x.2018.1511619

Den Hartigh, R. J. R., Hill, Y., \& Van Geert, P. L. C. (2018). The development of talent in sports: A dynamic network approach. Complexity. https://doi.org/10.1155/2018/9280154

Dohme, L. C., Backhouse, S., Piggott, D., \& Morgan, G. (2017). Categorising and defining popular psychological terms used within the youth athlete talent development literature: A systematic review. International Review of Sport and Exercise Psychology, 10(1), 134-163. https://doi.org/10.1080/1750984X.2016.1185451

Dohme, L. C., Piggott, D., Backhouse, S., \& Morgan, G. (2019). Psychological Skills and Characteristics Facilitative of Youth Athletes' Development: A Systematic Review. The Sport Psychologist, 33(4), 261-275. https://doi.org/10.1123/tsp.2018-0014

Duckworth, A. L., Peterson, C., Matthews, M. D., \& Kelly, D. R. (2007). Grit: Perseverance and passion for long-term goals. Journal of Personality and Social Psychology, 92(6), 1087-1101. https://doi.org/10.1037/0022-3514.92.6.1087

Dweck, C. S. (2008). Mindset: The new psychology of success. Ballantine Books. Egan, G. (2018). The skilled helper: A client-centered approach. Cengage.

Giacobbi, P. R., Poczwardowski, A., \& Hager, P. (2005). A pragmatic research philosophy for sport and exercise psychology. The Sport Psychologist, 19(1), 18-31. 
https://doi.org/10.1123/tsp.19.1.18

644

Harwood, C. (2008). Developmental consulting in a professional football academy: The 5Cs coaching efficacy program. The Sport Psychologist, 22, 109-133.

Henriksen, K. (2015). Developing a high-performance culture: A sport psychology intervention from an ecological perspective in elite orienteering. Journal of Sport Psychology in Action, 6(3), 141-153. https://doi.org/10.1080/21520704.2015.1084961

Hill, A., MacNamara, Á., \& Collins, D. (2019). Development and initial validation of the Psychological Characteristics of Developing Excellence Questionnaire version 2 (PCDEQ2). European Journal of Sport Science, 19(4), 517-528. https://doi.org/10.1080/17461391.2018.1535627

Kegelaers, J., \& Wylleman, P. (2019). Exploring the coach's role in fostering resilience in elite athletes. Sport, Exercise, and Performance Psychology, 8(3), 239-254. https://doi.org/http://dx.doi.org/10.1037/spy0000151

MacNamara, A., Button, A., \& Collins, D. (2010). The role of psychological characteristics in facilitating the pathway to elite performance Part 1: Identifying mental skills and behaviours. The Sport Psychologist, 24, 52-73. http://clok.uclan.ac.uk/4826/1/collins_4826.pdf

Michaels, C., \& Beek, P. (1995). The state of ecological psycholoogy. Ecological Psychology, $7(4), 259-278$.

Milavic, B., Padulo, J., Grgantov, Z., Milić, M., Mannarini, S., Manzoni, G. M., Ardigò, L. P., \& Rossi, A. (2019). Development and factorial validity of the Psychological Skills Inventory for Sports, Youth Version - Short Form: Assessment of the psychometric properties. PLoS ONE, 14(8), 1-17. https://doi.org/10.1371/journal.pone.0220930

O’Connor, E. A. J. (2004). Which questionnaire? Assessment practices of sport psychology consultants. The Sport Psychologist, 18(4), 464-468. 
668 Rees, T., Hardy, L., Güllich, A., Abernethy, B., Côté, J., Woodman, T., Montgomery, H.,

669

670

671

672

673

674

675

676

677

678

679

680

681

682

683

684

685

686

687

688

689

690

691

692

Laing, S., \& Warr, C. (2016). The Great British medalists project: A review of current knowledge on the development of the world's best sporting talent. Sports Medicine, 46(8), 1041-1058. https://doi.org/10.1007/s40279-016-0476-2

Scanlan, T. K., Chow, G. M., Sousa, C., Scanlan, L. A., \& Knifsend, C. A. (2016). The development of the Sport Commitment Questionnaire-2 (English version). Psychology of Sport \& Exercise, 22, 233-246. https://doi.org/10.1016/j.psychsport.2015.08.002

Sisk, V. F., Burgoyne, A. P., Sun, J., Butler, J. L., \& Macnamara, B. N. (2018). To what extent and under which circumstances are growth mind-sets important to academic achievement? Two meta-analyses. Psychological Science, 29(4), 549-571. https://doi.org/10.1177/0956797617739704

Smith, B. W., Dalen, J., Wiggins, K., Tooley, E., Christopher, P., \& Bernard, J. (2008). The brief resilience scale: Assessing the ability to bounce back. International Journal of Behavioral Medicine, 15(3), 194-200. https://doi.org/10.1080/10705500802222972

Smith, R. E., Schutz, R. W., Smoll, F. L., \& Ptacek, J. T. (1995). Development and validation of a multidimensional measure of sport-specific psychological skills: The athletic coping skills inventory-28. Journal of Sport and Exercise Psychology, 17(4), 379-398. https://doi.org/10.1123/jsep.17.4.379

Swann, C., Crust, L., Jackman, P., Vella, S. A., Allen, M. S., \& Keegan, R. (2017). Performing under pressure: Exploring the psychological state underlying clutch performance in sport. Journal of Sports Sciences, 35(23), 2272-2280. https://doi.org/10.1080/02640414.2016.1265661

Taber, K. S. (2018). The use of Cronbach's Alpha when developing and reporting research instruments in science education. Research in Science Education, 48(6), 1273-1296. https://doi.org/10.1007/s11165-016-9602-2 
693 Tedesqui, R. A. B., \& Young, B. W. (2018). Comparing the contribution of

694 conscientiousness, self-control, and grit to key criteria of sport expertise development.

$695 \quad$ Psychology of Sport and Exercise, 34, 110-118.

696 https://doi.org/10.1016/J.PSYCHSPORT.2017.10.002

697 Toering, T., Elferink-Gemser, M. T., Jonker, L., van Heuvelen, M. J. G., \& Visscher, C.

698 (2012). Measuring self-regulation in a learning context: Reliability and validity of the

699 Self-Regulation of Learning Self-Report Scale (SRL-SRS). International Journal of

$700 \quad$ Sport and Exercise Psychology, 10(1), 24-38.

$701 \quad$ https://doi.org/10.1080/1612197X.2012.645132

702 Vealey, R. S. (1988). Future directions in psychological skills training. The Sport

703 Psychologist, 2(4), 318-336. https://doi.org/https://doi.org/10.1123/tsp.2.4.318

704 Wylleman, P., \& Rosier, N. (2016). Holistic perspective on the development of elite athletes.

705 In M. Raab, P. Wylleman, R. Seiler, A.-M. Elbe, \& A. Hatzigeorgiadis (Eds.), Sport and

706 Exercise Psychology Research: From Theory to Practice (pp. 270-282). Elsevier. 
708 Table 1.

709 Descriptive statistics, internal consistency and correlations with coach rankings

\begin{tabular}{lllllll}
\hline Competency & Items & $\mathrm{M}$ & SD & Range & $\alpha$ & $r_{\mathrm{s}}$ \\
\hline Coachability & 4 & 2.44 & 0.37 & $2.50-4.00(1-4)$ & .58 & -.16 \\
Reflection & 5 & 3.17 & 0.40 & $3.40-5.00(1-5)$ & .73 & -.19 \\
Growth mindset & 12 & 2.92 & 0.34 & $3.08-4.83(1-5)$ & .65 & $-.46^{*}$ \\
Commitment & 6 & 3.42 & 0.46 & $3.17-5.00(1-5)$ & .83 & -.14 \\
Confidence & 3 & 2.34 & 0.66 & $1.67-4.67(1-5)$ & .85 & -.41 \\
Competitiveness & 5 & 3.20 & 0.39 & $3.40-5.00(1-5)$ & .39 & -.11 \\
Focus & 4 & 1.74 & 0.47 & $1.50-3.75(1-4)$ & .58 & -.33 \\
Resilience & 6 & 2.34 & 0.49 & $2.50-4.33(1-5)$ & .72 & $-.47^{*}$ \\
Perseverance & 6 & 2.91 & 0.48 & $2.67-5.00(1-5)$ & .68 & .20 \\
Being a team player & 3 & 3.01 & 0.43 & $3.25-4.75(1-5)$ & .53 & -.35 \\
\hline * $p<.05$ & & & & & &
\end{tabular}


Table 2.

Pearson correlation coefficients between the psychological characteristics

\begin{tabular}{|c|c|c|c|c|c|c|c|c|c|c|}
\hline & $\mathrm{CB}$ & $\mathrm{RF}$ & GM & $\mathrm{CM}$ & $\mathrm{CF}$ & $\mathrm{CO}$ & $\mathrm{FO}$ & $\mathrm{RE}$ & $\mathrm{PE}$ & $\mathrm{TP}$ \\
\hline $\mathrm{CB}$ & - & & & & & & & & & \\
\hline RF & .06 & - & & & & & & & & \\
\hline GM & .27 & -.12 & - & & & & & & & \\
\hline $\mathrm{CM}$ & .30 & .02 & .21 & - & & & & & & \\
\hline $\mathrm{CF}$ & .20 & .03 & .18 & .07 & - & & & & & \\
\hline $\mathrm{CO}$ & .27 & $.42 * *$ & .00 & .27 & -.08 & - & & & & \\
\hline FO & $.38 *$ & -.12 & .06 & .20 & .20 & -.15 & - & & & \\
\hline RE & $.31 *$ & .28 & .24 & .15 & $.34 *$ & .19 & .20 & - & & \\
\hline PE & .22 & .23 & -.04 & .04 & .28 & $.37 *$ & .04 & .08 & - & \\
\hline ТP & .08 & $.31^{*}$ & .15 & .28 & .24 & .29 & .15 & .19 & $.35^{*}$ & - \\
\hline
\end{tabular}

712 Note: Coachability (CB), Reflection (RF), Growth mindset (GM), Commitment (CM),

713 Confidence (CF), Competitiveness (CO), Focus (FO), Resilience (RE), Perseverance (PE)

714 and being a team player (TP). 